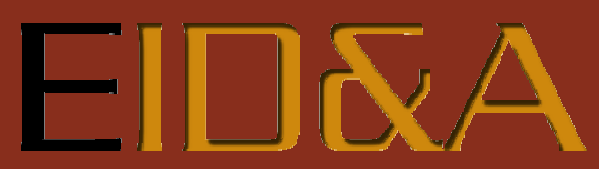

Revista Eletrônica de Estudos Integrados em Discurso e Argumentação

http://dx.doi.org/10.17648/eidea-15-1792

\title{
METALINGUAGEM COMO RECURSO ARGUMENTATIVO EM TEXTOS RELIGIOSOS ${ }^{i}$
}

\author{
Roberlei Alves Bertuccii
}

Resumo: Este trabalho tem como objetivo analisar as ocorrências de recursos metalinguísticos em textos religiosos. Considerando que a argumentatividade é inerente à linguagem, defendemos que esses recursos servem de estratégia argumentativa na defesa de uma tese e estabelecem relações de identidade ou transitividade entre os fatos, conforme Perelman e Olbrechts-Tyteca (2014). Isso ocorre porque os autores dos textos religiosos fazem uso da metalinguagem com o objetivo de apresentar uma relação mais clara entre a expressão referida e a ideia religiosa veiculada por ele. Com isso, há uma clara identidade entre o conceito e essa ideia, o que caracteriza uma construção argumentativa importante nesses textos em que o orador pretende a adesão do auditório por meio de seu discurso. Para a análise, selecionamos textos de comentários religiosos em que a metalinguagem aparecia especialmente na forma de etimologia.

Palavras-chave: Metalinguagem. Textos religiosos. Argumentação. Argumento de definição.

Abstract: This work aims to analyze some occurrences of metalanguage resources in religious texts. We assume that argumentativeness is inherent to natural language $(\mathrm{KOCH}, 2011)$ and we argue that these resources are used as an argumentative strategy to defend a point of view and they are related to notions as identity and transitivity arguments (PERELMAN e OLBRECHTS-TYTECA, 2014). In this case, authors use metalanguage in order to construct a strong relation between one expression and their thesis and, after that, to obtain auditorium adhesion through their discourse. Our analyses are based on some comments about religious texts in which metalanguage arises as etymological explanations.

Keywords: Metalanguage. Religious texts. Argumentation. Definitions in argumentation.

\footnotetext{
Expresso meus mais sinceros agradecimentos aos integrantes dos grupos de estudos em Semântica e Tecnologia e Estudos de Argumentação, da UTFPR, cujas discussões em 2017 deram origem ao presente trabalho. Agradeço também aos comentários dos pareceristas anônimos desta revista, fundamentais para qualificar o trabalho. Problemas remanescentes são de minha responsabilidade.

ii Professor Doutor da Universidade Tecnológica Federal do Paraná (UTFPR), Brasil. Email: bertucci@utfpr.edu.br.
} 
EID\&A - Revista Eletrônica de Estudos Integrados em Discurso e Argumentação, llhéus, n. 15, jan./jun.2018.

\section{Introdução}

A argumentação tem sido colocada em foco nos estudos em linguagem, esta encarada como meio de produção de interações sociais. Autores como Ducrot (1987), Koch (2011), Perelman e Olbrechts-Tyteca (2014) e Fiorin (2017), entre outros, defendem que é próprio da língua se pautar por um caráter argumentativo, no sentido que as escolhas linguísticas dos falantes constroem opções específicas de sentidos para seus discursos. É com tais escolhas que construímos um percurso argumentativo capaz de convencer um auditório (PERELMAN e OLBRECHTS-TYTECA, 2014), compartilhado nas interações linguísticas (DUCROT, 1987; KOCH, 2011).

Nesse sentido, os textos religiosos parecem ser uma fonte interessante de estudo de argumentação: neles, além da avaliação, da crítica, da análise, há, sem dúvida, uma tentativa de influenciar no comportamento do outro, de convencê-lo, de torná-lo um seguidor daquela ideologia. Por essa razão, selecionamos para este trabalho alguns exemplares de textos religiosos, mais especificamente de comentários sobre passagens bíblicas, em que os autores, com maior ou menor conhecimento técnico (teológico) explicam esses trechos. Vamos defender que seu objetivo, acompanhando o que dissemos acima, é de influenciar o comportamento do seguidor, esperando uma maior adesão à proposta. Nosso foco será no modo como eles utilizam recursos metalinguísticos para a construção argumentativa de seus textos.

Para isso, vamos apresentar a noção de argumentação e alguns tipos de argumentos presentes em Perelman e Olbrechts-Tyteca (2014), além de alguns comentários de Wachowicz (2010) e Fiorin (2017) sobre esses tipos. ' Vamos propor que a metalinguagem, ou seja, a inserção de informações sobre a própria língua em textos religiosos tem relação direta com a tese a ser defendida pelos autores, sendo relacionada, mais especificamente, a noções de definição e transitividade na teoria de Perelman e Olbrechts-Tyteca.

Há quase 20 anos, Gomes-da-Silva (1999) já defendia que a metalinguagem na imprensa estaria ligada à construção e à argumentação dos textos. No trabalho, porém, a autora tratava também de ocorrências estruturais (tamanho e posição de chamada ou título), de recursos de escrita, como aspas, além das ocorrências ditas metadiscursivas, em geral com modalizadores, em que havia o destaque a um dos argumentos do autor no

\footnotetext{
${ }^{1}$ A edição de Perelman e Olbrechts-Tyteca (3.ed. 2014) que estamos utilizando é mais recente que aquela de Wachowicz (1.ed. 1996) e Fiorin (2.ed. 2005).
} 
EID\&A - Revista Eletrônica de Estudos Integrados em Discurso e Argumentação, llhéus, n. 15, jan./jun.2018.

texto. No presente artigo, nosso objetivo é tratar de ocorrências metalinguísticas relacionadas estritamente a comentários sobre o código linguístico - sobre a etimologia, por exemplo - e argumentar que esse recurso está diretamente ligado ao argumento utilizado pelo autor para a defesa (ou refutação) de uma tese.

Vamos apresentar uma diferenciação entre conhecimento epilinguístico e metalinguístico, defendendo que este tem papel decisivo no modo como os autores constroem sua tese sobre um ponto religioso específico.

\section{Argumentação e linguagem \\ 1.1. Definição de argumentação}

Ao se considerar a argumentatividade como parte da natureza da língua, no sentido de que toda fala aponta para uma direção, devemos levar em conta os recursos retóricos que são capazes de sustentar essa direção. Assim, entendemos que os sentidos para os quais um texto nos aponta são sempre dados linguisticamente.

Nesse sentido, vamos assumir com Fiorin (2017, p. 69) que "um argumento são proposições destinadas a fazer admitir uma dada tese. Argumentar é, pois, construir um discurso que tem a finalidade de persuadir". Dessa forma, o objetivo da argumentação é "provocar ou aumentar a adesão dos espíritos às teses que se apresentam a seu assentimento" (PERELMAN e OLBRECHTS-TYTECA, 2014, p. 50). Nesse processo, três elementos estão intimamente imbricados: orador, auditório e discurso. Ao orador, cabe construir seu discurso de modo a persuadir o auditório e, por isso, investigar as estratégias dessa construção é essencial para o entendimento da estrutura argumentativa na linguagem.

Perelman e Olbrechts-Tyteca consideram que os argumentos são construídos em duas bases fundamentais: por ligação, em que se procura unir fatos, ou por dissociação, em que se pretende separá-los. Neste trabalho, vamos considerar que a metalinguagem é um recurso que permite a associação entre fatos, mais especificamente, entre a etimologia/significado de uma expressão e o objeto ou evento a que se refere, o que a colocaria como um argumento por ligação, mais especificamente, um argumento quase lógico. $\mathrm{Na}$ seção 2, vamos apresentar mais sobre as questões de metalinguagem. A seguir, nos deteremos um pouco mais nos argumentos 
EID\&A - Revista Eletrônica de Estudos Integrados em Discurso e Argumentação, llhéus, n. 15, jan./jun.2018.

quase lógicos, já que nossa hipótese é de que a metalinguagem contribui para sua construção no texto.

\subsection{Os argumentos quase lógicos}

Como nosso foco neste artigo é apresentar a metalinguagem como um recurso argumentativo, vamos nos concentrar na descrição dos argumentos quase lógicos, considerando a subdivisão de Perelman e Olbrechts-Tyteca (2014) sobre os tipos de argumentos por ligação. Os quase lógicos "pretendem certa força de convicção, na medida em que se apresentam como comparáveis a raciocínios formais, lógicos ou matemáticos" (PERELMAN e OLBRECHTS-TYTECA, 2014, p. 219). Por razões de espaço (e foco), vamos diretamente aos subtipos que se apresentam como os mais compatíveis com os recursos metalinguísticos encontrados nos textos: definição e transitividade.

\subsubsection{Argumento de definição}

Para ressaltar a importância do argumento de identidade, Perelman e Olbrechts-Tyteca (2014, p. 238) observam que

[...] uma das técnicas essenciais da argumentação quase-lógica é a identificação de diversos elementos que são o objeto do discurso. Todo uso de conceitos, toda aplicação deuma classificação, todo recurso à indução implica uma redução de certos elementos ao que neles há de idêntico ou de intercambiável.

Em outras palavras, os autores consideram que a identificação é uma estratégia argumentativa importante na defesa (ou refutação) de uma tese, já que estabelece uma relação direta $(a=b)$. Para o presente trabalho, é importante ainda assinalar alguns pontos indicados pelos autores: o primeiro é que termos diferentes podem ter uma mesma definição ou termos semelhantes podem ter definições diferentes (em línguas distintas, por exemplo). Nesse caso, o orador poderá utilizar-se de um ou outro para trilhar o caminho argumentativo de seu texto. O segundo ponto é relativo à interação entre os termos envolvidos na definição, os quais formam um conjunto entre si, entre termos semelhantes ou diferentes na mesma língua ou em línguas diferentes.

Neste subtipo de argumento quase lógico, há uma relação de identidade entre duas partes, a partir de características intensionais ou extensionais, 
EID\&A - Revista Eletrônica de Estudos Integrados em Discurso e Argumentação, llhéus, n. 15, jan./jun.2018.

adjetivos, funções entre outros (FIORIN, 2017). Wachowicz (2010, p. 105) afirma que esses argumentos são, em geral, introduzidos por "verbos indicadores de significado, como ser, significar, designar etc., no formato da sentença de definição do tipo X é Y".

Neste trabalho, vamos defender a hipótese de que o uso da metalinguagem pode estar relacionado ao argumento por definição, sendo uma estratégia importante em textos do universo religioso, sobretudo quando tratam da etimologia dos termos, o que significa a relação com um termo de outra língua. Veremos nas seções 3 e 4 como isso forma um argumento robusto em textos dessa temática.

\subsubsection{Argumento de transitividade}

Outro subtipo importante dentro dos quase lógicos são os argumentos de transitividade. Perelman e Olbrechts-Tyteca (2014, p. 257) afirmam que:

[...] a transitividade é uma propriedade formal de certas relações que permite assar da afirmação de que existe a mesma relação entre os termos $a$ e $b$ e entre os termos $b$ e $c$, à conclusão de que ela existe entre os termos $a$ e $c$ : as relações de igualdade, de superioridade, de inclusão, de ascendência são relações transitivas.

Como afirma Fiorin (2017), a transitividade estabelecida pela relação se $a=b$ e $b=c$, então $a=c$ é um caso de consequência necessária; mas, na perspectiva retórica, de argumentos quase lógicos, é uma consequência provável ou possível. Na verdade, como ocorre com outros casos, essa consequência é estabelecida pelo orador, no discurso, que estabelece a transição de um elemento entre fatos distintos.

Perelman e Olbrechts-Tyteca (2014) sublinham também a importância das relações de transitividade por implicação, já que a construção de silogismos é baseada exatamente nessas relações de transitividade.

Ao longo de nossa pesquisa, observamos que alguns usos metalinguísticos eram fundamentais para estabelecer uma relação de transição, por exemplo, entre o significado de um texto e um fato específico. Assim, neste trabalho, levantamos a hipótese de que algumas ocorrências de metalinguagem têm relação direta com a transitividade na construção argumentativa de um texto. 
EID\&A - Revista Eletrônica de Estudos Integrados em Discurso e Argumentação, llhéus, n. 15, jan./jun.2018.

\section{Linguagem, epilinguagem e metalinguagem}

Franchi (1992, p. 25) defende que a linguagem tem uma função que vai além da comunicação, sendo instrumento vital para a racionalidade humana: "a função de comunicar não é a função única, nem mesmo a função essencial da linguagem: ela permite antes a reflexão e o pensamento." Assim, podemos dizer que, ao tomar a linguagem como instrumento essencial para suas abstrações, o homem é capaz de agir por meio dela. Por isso, neste trabalho, vamos assumir a linguagem como um instrumento humano de ação sobre o mundo e as pessoas. E, ao tomarmos a argumentatividade como uma característica intrínseca às línguas naturais, razão pela qual perpassa todos os discursos (DUCROT, 1987; KOCH, 2011; PERELMAN e OLBRECHTS-TYTECA, 2014; FIORIN, 2017), vamos considerar que a ação linguística do homem se dá primordialmente pela argumentação. Ao escolher expressões específicas para desenvolver seus raciocínios, o ser humano orienta seu discurso para determinado fim. Nesse sentido, pode-se afirmar que todo falante nativo tem a capacidade de escolher expressões adequadas aos objetivos que pretende em uma dada situação de interação do cotidiano. ${ }^{2}$ A essa capacidade de uso linguístico Antoine Culioli denomina epilinguismo, sendo ela racional; por ela, o falante utiliza fluentemente sua língua, sem que precise refletir sobre cada uma de suas estruturas: uma vez adquirida, a habilidade é natural (CULIOLI e NORMAND, 2005).

Por outro lado, a linguagem (ou discurso) que conduz as interações pode ser estudada, classificada, rotulada, explicada: é o aspecto metalinguístico que ressalta aqui. Para Culioli, o conhecimento metalinguístico faz parte da racionalidade do pesquisador, o qual busca nos vestígios da linguagem o conhecimento intrínseco ao falante (epilinguístico) e tenta sistematizar esse conhecimento (metalinguístico). Por isso, Romero (2011, p. 193) comenta que o raciocínio metalinguístico consiste em uma "representação-simulação" do que se passa na fonte (conhecimento epilinguístico).

Tal reflexão possibilitou ao ser humano construir um conjunto de conhecimentos capazes de permitir o entendimento sobre a complexidade do sistema, bem como a tentativa de aproximar os sistemas linguísticos. Para esse processo, o desenvolvimento da escrita foi essencial, bem como para o

\footnotetext{
${ }^{2}$ Salvo incapacidade de saúde, como afasias em geral, ou exigência de gêneros específicos, como uma defesa num tribunal, por exemplo, que requerem um conhecimento maior.
} 
EID\&A - Revista Eletrônica de Estudos Integrados em Discurso e Argumentação, llhéus, n. 15, jan./jun.2018.

desenvolvimento das ciências de modo geral. À medida que registros poderiam ser feitos, mais replicados poderiam ser os experimentos e mais debatidas as ideias. E, com isso, a metalinguagem passou a exercer um papel importante: ao registrar os textos por escrito é possível recuperar as informações mais relevantes algum tempo depois. Mas, acima de tudo, é possível também lançar mão dos conhecimentos sobre a língua para desenvolver o texto. É o que pretendemos mostrar nesta pesquisa com os textos religiosos.

Tomando por base as noções apresentadas, especialmente a proposta de Culioli, vamos definir metalinguagem como a operação racional e consciente sobre a linguagem, seja ela feita por um pesquisador, seja ela feita pelo próprio falante, ou seja, não consideramos que seja, necessariamente, um "estudo sobre a linguagem". Nosso foco será no emprego metalinguístico sobre as expressões utilizadas, quer sobre sua etimologia, quer sobre sua classificação.

Assim, vamos considerar que os textos produzidos são produtos linguísticos, fruto da capacidade epilinguística dos falantes. No entanto, vamos defender que a metalinguagem, quando empregada nos textos, tem um papel importante na orientação argumentativa: o orador faz uso de um conhecimento além da língua (metalinguístico) para produzir um efeito discursivo sobre o auditório pela própria língua (no texto). Nesse sentido, podemos dizer que a gramatização passa a ser um recurso importante no processo, o que vai ao encontro da reflexão de Auroux (2014), para quem o saber metalinguístico é tripartite: o primeiro ligado à capacidade de expressão das ideias; o segundo à compreensão da própria língua em relação a outras; e o terceiro à capacidade de desenvolver técnicas e práticas letradas, ou seja, de escrita.

Ao desenvolvermos a próxima seção, em que analisaremos textos religiosos, queremos responder a seguinte pergunta: de que modo a reflexão sobre a língua, ou seja, a metalinguagem, pode ser um instrumento de construção argumentativa no texto? Nossa hipótese é de que o uso da metalinguagem se constitui um argumento quase lógico, especialmente de definição e/ou transitividade, de modo que o autor pretende orientar 0 discurso para sua tese. 
EID\&A - Revista Eletrônica de Estudos Integrados em Discurso e Argumentação, llhéus, n. 15, jan./jun.2018.

\section{Metalinguagem e argumentação em textos religiosos}

Sem dúvida, a escrita foi uma grande revolução, como afirma Auroux (2014): propiciou o acúmulo e a transmissão de descobertas e de práticas culturais de diferentes comunidades que até então só tinham a oralidade como meio de circulação do saber. Nesse aspecto, a religião não ficou de fora, já que a escrita possibilitou a fixação de normas e filosofias religiosas, especialmente por meio de seus livros sagrados (XAVIER, 2013). De algum modo, também propiciou o debate sobre os mesmos textos, já que sua interpretação nem sempre é consensual; mais que isso, quando se comparam as diferentes versões bíblicas, há casos de significados bem distintos entre si, o que interfere na adesão do auditório ao discurso veiculado.

Nesta pesquisa, longe de se verificar a adequação de uma versão, nossa intenção é mostrar que as pessoas que comentam passagens bíblicas (teólogos ou leigos) podem se utilizar de recursos metalinguísticos para dar ênfase a um argumento expresso no comentário. Nesse sentido, os textos escolhidos são escritos por pessoas religiosas, com maior ou menor formação na área e são direcionados a todos os que desejam entender melhor as referidas passagens. Alguns textos (os roteiros homiléticos da revista Vida Pastoral, por exemplo, que são roteiros para os sermões dos padres, chamados de homilias) parecem mais técnicos que outros, embora todos sejam acessíveis aos leitores interessados. Em geral, todos têm em comum o fato de refletir sobre o texto de modo a levar o leitor assimilar a passagem e se tornar um seguidor mais maduro da proposta cristã. Ainda é importante dizer que a intenção deste artigo não é catequética; os textos religiosos foram escolhidos porque, além de serem um modo de ação linguístico, presente na realidade de muitas pessoas, apresentam grande ocorrência de metalinguagem.

Passamos, a seguir, à análise dos textos escolhidos. Os três primeiros textos são de religiosos teólogos, estudiosos dos textos bíblicos; os dois últimos são de autores leigos, mas que estudam a Bíblia e propõem reflexões sobre as passagens lidas. Esses textos foram publicados nos sites Dom Total, Vida Pastoral e Lectionautas, todos ligados ao catolicismo: os dois primeiros mais técnicos (com colaboradores teólogos, em grande parte) e o último mais "popular", no sentido que seus escritores não são definidos como teólogos, mas como leigos que contribuem com reflexões diárias sobre os evangelhos. Todos os textos escolhidos versam sobre passagem dos evangelhos, que são o ponto central de reflexão para a fé da religião em questão, e se destacam pelo uso explícito de 
EID\&A - Revista Eletrônica de Estudos Integrados em Discurso e Argumentação, llhéus, n. 15, jan./jun.2018.

metalinguagem no texto. Nossa hipótese é de que a utilização da metalinguagem nesses textos ocorre porque ela se torna uma estratégia relacionada aos argumentos quase lógicos na proposta de Perelman e Olbrechts-Tyteca (2014). Por questões de espaço, colocaremos apenas os trechos de análise, deixando os links completos para conferência do texto completo pelo leitor.

\section{Texto 1 - PALAORO (2018). Palavras que destravam a vida (grifos do autor)}

[...] De Jesus diziam que "ensinava com autoridade" e não como os escribas e fariseus.

Ele tinha a graça de conceder autoridade a cada pessoa, de devolver-lhe sua dignidade, de

remeter-lhe a si mesma, de ajudá-la a conectar com seu ser profundo, com aquilo que é

mais divino no próprio interior.

Ensina com autoridade quem fala a partir de sua própria experiência e quem, com seu

ensinamento, "faz crescer" (a palavra "autoridade" provém do verbo latino "augere", que

significa aumentar, fazer crescer, elevar o outro... ); em outras palavras, é despertar a

autonomia e a autoria do outro para que ele seja capaz de dar direção à própria vida. [...]

É extraordinário perceber como as palavras ditas com cuidado e amor (pedagogia de

Jesus) produzem efeitos benéficos para o ser humano. Essas palavras são bem

aventuradas, pois são capazes de fazer crescer, sustentar, edificar as pessoas para o

convívio social, humano-afetivo, espiritual. São palavras que trazem luz e calor, infundem confiança e segurança.

13 A palavra tem força de ressurreição, é como brisa suave que ativa nossas melhores energias.

Fonte: http://domtotal.com/noticia/1226500/2018/01/palavras-que-destravam-a-vida/

Nas linhas 6 e 7, vemos que Palaoro utiliza a etimologia da palavra autoridade (augere, em latim) para explicar por que o autor do texto disse que Jesus ensinava com autoridade. Neste caso, Palaoro defende que essa autoridade está relacionada com o crescimento das pessoas que encontravam Jesus. Para atestar nossa hipótese de que o autor utiliza essa metalinguagem como estratégia argumentativa, podemos ler entre as linhas 9 e 13, que correspondem aos dois últimos parágrafos do texto completo, que o autor retoma a noção de autoridade para concluir sua tese: a autoridade de Jesus tem relação direta com o crescimento da pessoa que o segue (que o encontra), por isso sua palavra (neste caso, sinônimo de autoridade) "tem força de ressurreição", para o autor. A metalinguagem, portanto, mais que uma mera explicação da origem de uma expressão visa a defesa de um ponto de vista sobre como seria a autoridade exercida no ministério de Cristo e que, por consequência, deve ser aquela esperada por (e de) seus seguidores.

No Texto 1, o argumento de definição se dá pela etimologia da palavra autoridade, definida como "fazer crescer". Ali, Palaoro defende a autoridade do ensinamento de Jesus como algo legítimo e de benefício ao ser humano, ao contrário do que se poderia pensar, como uma condição de superioridade hierárquica sem motivação. Nesse sentido, a definição se relaciona com a 
EID\&A - Revista Eletrônica de Estudos Integrados em Discurso e Argumentação, llhéus, n. 15, jan./jun.2018.

argumentação por transitividade e, para isso, poderíamos pensar na seguinte relação:

a) Se autoridade é fazer crescer;

b) Se o ensinamento de Jesus tem autoridade;

Logo,

c) O ensinamento de Jesus faz crescer.

Ao mesmo tempo, outra noção de transitividade fica implícita: a de que um ensinamento com autoridade é esperado por (e de) os seguidores de Jesus. Isso fica mais claro ainda quando, ao fechar o texto, Palaoro (2018) convida seus leitores a pensar sobre o seguinte ponto

Devemos expulsar muitos "maus espíritos" interiores (ânsia de poder, riqueza, prestígio, vaidade...) que jogam ao chão nossa dignidade e impedem um testemunho coerente, uma verdadeira autoridade que profere palavras que fazem as pessoas crescer.

O autor argumentar que o testemundo cristão, ou seja, o que se espera de seus seguidores, é exatamente que "profiram palavras com autoridade", assim como Jesus fazia. Se for assim, o testemundo contribuirá para o crescimento do outro, um elemento que se identifica com a origem da palavra autoridade, conforme discutido anteriormente. Passemos ao segundo texto.

\section{Texto 2 - KONINGS, Johan (2018). Vida Pastoral (grifos do autor)}

\footnotetext{
[...] Como Jonas, na $1^{\text {a }}$ leitura, Jesus aparece como profeta apocalíptico, mas, em vez de uma catástrofe, anuncia a boa-nova da chegada do Reino e pede conversão e fé. E isso com a "autoridade" do Reino que se revela na expulsão de demônios e outros sinais (Mc 1,22.27). Ele é o "Filho de Deus" $(1,1 ; 9,7 ; 15,39 ;$ cf. 1,11).

Mas por que essa mensagem exige conversão? A mensagem de Jonas logrou êxito e produziu penitência à base do medo; a mensagem de Cristo solicita conversão à base da fé na boa-nova. Observe-se que conversão não é a mesma coisa que penitência. Certas Bíblias traduzem, erroneamente, Mc 1,15 como "fazei penitência" em vez de "convertei-vos". Penitência tem que ver com pena, castigo. Conversão é dar nova virada à vida. O grego metanoia sugere uma mudança de mentalidade.

Por trás disso está o hebraico shuv, "voltar" (a Deus), não por causa do medo, mas por causa da confiança no dom de Deus, o "reino de Deus", que é o acontecer da vontade amorosa do Pai, como reza o pai-nosso: "Venha o teu reino, seja feita a tua vontade". Onde reinam o amor e a justiça, conforme a vontade de Deus, acontece o reino de Deus. Na medida em que Jesus se identifica com essa vontade e a cumpre até o fim, até a morte, ele realiza e traz presente esse reino em sua própria pessoa. Ele é o reino de Deus que se torna presente. Todo o Evangelho de Marcos desenvolve essa verdade. [...]

É este o programa da Igreja, chamada a continuar a missão de Jesus: o anúncio da vontade de Deus e

19 de sua oferta de graça ao mundo; a vocação, formação e envio de pessoas que se dediquem ao anúncio; e a orientação de todos para a participação no reino de Deus, vivendo na justiça e no amor.
}

Fonte: http://www.vidapastoral.com.br/roteiros/30-domingo-do-tempo-comum-21-dejaneiro/ 
EID\&A - Revista Eletrônica de Estudos Integrados em Discurso e Argumentação, Ilhéus, n. 15, jan./jun.2018.

Neste texto, ao apresentar a origem do termo conversão (voltar, mudar a mentalidade), em especial nas linhas 9 e 10, Konings defende sua relação com a construção do reino de Deus no texto do evangelista Marcos. Para o teólogo, esse termo não tem relação direta com penitência (ele inclusive faz críticas às versões que fazem uso dessa expressão). Na explicação do trecho, em especial a partir da linha 10, o autor argumenta que essa conversão indicada é uma "volta a Deus", sendo realizada no amor, na justiça e na paz (reino de Deus); no final do texto, a partir da linha 18, o autor defende que essa conversão (volta; construção do reino) é de responsabilidade da Igreja, ou seja, de todos aqueles que dizem se identificar com a pessoa e a missão de Jesus. Novamente, como no primeiro caso, vemos que o autor usa o recurso metalinguístico (neste caso, as origens grega e hebraica da palavra) para a defesa de um ponto de vista.

No Texto 2, Konings também utiliza uma definição para construir seu argumento, identificando conversão com a noção de voltar a Deus ou mudar de mentalidade, em vistas da construção do seu reino. Nesse sentido, novamente a noção de transitividade se verifica, da seguinte maneira:

a) Se conversão é voltar a Deus;

b) Se voltar a Deus é construir o seu reino;

Logo,

c) A conversão é a construção do reino de Deus.

Por isso, diferentemente do Texto 1, não se poderia tratar de transitividade aos seguidores de Cristo, já que a conversão deve ser um ato deles e não caberia a Jesus, entendido como o próprio Filho de Deus.Logo, ainda que o recurso metalinguístico no leve a identificar o argumento do autor a respeito da necessidade de conversão, não é necessariamente algo que passa de Jesus a seus seguidores, mas dos convertidos a Deus, conforme o texto evangélico, aos que hoje se convertem, ainda que seja Jesus o modelo ideal do convertido. Seguimos ao texto 3 . 
EID\&A - Revista Eletrônica de Estudos Integrados em Discurso e Argumentação, Ilhéus, n. 15, jan./jun.2018.

\title{
Texto 3 - ANDRADE, Aíla L. Pinheiro de (2017). Vida Pastoral
}

\begin{abstract}
[...] As bem-aventuranças, em seu conjunto, constituem um estilo de vida, uma mensagem de esperança e uma ordem de batalha para aqueles que lutam pela implantação do reino dos céus e anseiam por sua chegada definitiva. O ponto de partida das bem-aventuranças são as condições concretas da vida humana. Há pessoas que choram, são injustiçadas, perseguidas, injuriadas e caluniadas por causa do reino dos céus e ainda assim permanecem mansas, pacificadoras, misericordiosas e puras.

No idioma de Jesus, o termo geralmente traduzido por "bem-aventurados" ou "felizes" é o imperativo dos verbos "avançar" e "prosseguir" (cf. Pr 4,14). Em um contexto de perseguição, as palavras de Jesus também podem ser assim traduzidas:

[...] Que avancem todos aqueles que "promovem a paz" ou que produzem o shalom (prosperidade, bem, saúde, inteireza, segurança, integridade, harmonia e realização). Serão chamados filhos de Deus, o verdadeiro doador da paz. [...]

Muitas pessoas passam por grandes sofrimentos e se afastam da Igreja porque não encontram explicações ou porque lhes foram dadas explicações desastrosas para suas angústias e sofrimentos. Se a Igreja é solidária com o sofredor, ele se sentirá seguro para permanecer fiel, mesmo sem entender o sofrimento que o sufoca.

Muitas vezes as desistências ou o distanciamento das pessoas em relação à lgreja são decorrentes da promessa de um cristianismo fácil e confortável, como retribuição pelas boas obras. Mas quando as dificuldades se anunciam, como é próprio da vida humana, as pessoas não têm a força interior para se manterem fiéis.
\end{abstract}

Fonte: http://www.vidapastoral.com.br/roteiros/todos-os-santos-5-de-novembro/

O trecho explicado por Andrade é conhecido como o das bemaventuranças. Nele, a autora apresenta dois momentos de uso metalinguístico: o primeiro, linhas 7 a 9, quando apresenta que "felizes" ou "bem-aventurados" são imperativos dos verbos "avançar/prosseguir" no idioma de Jesus; o segundo, na linha 10, quando apresenta, entre parênteses o significado para shalom. No primeiro caso, o que chama a atenção é a relação entre "lutar/avançar" e "ser bem-aventurado/feliz" feita pela autora: à medida que estabelece a raiz/origem dos termos, defende a ideia de que as bemaventuranças são "um estilo de vida" daqueles que devem avançar para a construção do reino de Deus. No segundo caso, é importante destacar que, ao apresentar o amplo significado de shalom, a autora deixa subentendido como a construção da paz (shalom) é algo difícil, por envolver uma série de estados e, por isso, devem ser "bem-aventurados" aqueles que lutam por ela. Os trechos iniciais, como se viu nos trechos anteriormente analisados, são retomados no desfecho do texto de Andrade: se a Igreja, ou seja, os seguidores de Jesus, acolhem o sofredor (o que luta) e deixa claro que a construção do reino de Deus é algo difícil, as pessoas continuarão fiéis ao propósito, ou seja, prosseguirão, avançarão nessa construção. Do contrário, haverá desilusão. 
EID\&A - Revista Eletrônica de Estudos Integrados em Discurso e Argumentação, llhéus, n. 15, jan./jun.2018.

Andrade, no Texto 3, identifica a noção de bem-aventurança com a de avançar/prosseguir, claramente um uso de argumento de definição. No texto, a autora indica uma transitividade entre essa definição e aqueles que lutam, ou seja, que tentam avançar/prosseguir: são estes os bem-aventurados de quem Jesus fala. Novamente, como no Texto 1, mas diferente do Texto 2, se estabelece outra relação de transitividade, agora referente aos seguidores de Jesus (à Igreja): estes devem avançar, prosseguir, lutar e estar ao lado de quem passa por dores durante a luta; não é um cristianismo de promessas ou conquistas que se deve viver/pregar, mas um cristianismo de luta (linhas 13 a 20).

\title{
Texto 4 - FERREIRA, Ana Paula (2018). Jejum.
}

\begin{abstract}
Várias são as referências no Antigo Testamento apontando para uma ordem de Deus para que o povo se dedicasse à prática do jejum. A expressão hebraica usada para designar uma atitude que levava a esse hábito era 'anah nephesh', que significa afligir a alma. Trata-se de um dia que, inicialmente, era guardado pelo povo de Israel e que, depois, passou a ser acompanhado pelo sacrifício do alimento. Sacrifício para expiação dos pecados cometidos. Incomoda aos questionadores de Jesus o fato de seus seguidores não seguirem essa tradição, mas Jesus discorda deles.

Se basearmos nossa interpretação no que a palavra "jejum" significa (como definido acima), sendo Jesus motivo de alegria, como ficarmos aflitos em sua companhia? A parábola do noivo, sob esse aspecto, faz todo o sentido. Ao citar a festa de casamento, o significado atribuído ao jejum por Jesus é o mesmo entendido pelas pessoas que o cercavam: tristeza profunda. Ora, não poderíamos nos entristecer em uma festa de casamento, sobretudo se considerarmos que Jesus é o noivo citado texto. Jesus é o noivo de uma nova aliança que Deus propõe a nós. Uma aliança que quebra os medos e a rigidez do Antigo Testamento para instaurar a prática do Amor. Devemos nos lembrar ainda de que o jejum do tempo de Jesus já havia se tornado uma prática seguida mais pela tradição que pelo coração, de fato, uma prática já quase destituída de sentido, em que as pessoas estavam mais preocupadas com a tristeza aparente que com aquela do interior.
\end{abstract}

Fonte: http://www.lectionautas.com.br/2018/jejum/

Neste trecho, Ferreira faz alusão à origem hebraica de jejum (linha 3), como aflição da alma, um dia guardado pelo povo para mortificação interior. Dessa forma, percebe-se que a palavra não teria apenas o significado de abstenção de algo, mas de uma angústia, que provocaria tristeza na pessoa. Ferreira usa esse significado para mostrar, a partir da linha 7, que jejum e Jesus não são compatíveis (pelo menos não no trecho analisado), já que este é causa de alegria, “o noivo da festa da nova Aliança”. Percebe-se que, no texto, a autora apresenta um sentido para a palavra jejum, por meio de sua etimologia, que vai além daquele que se conhece, de abstinência. Com tal apresentação, ela explica o trecho bíblico em que as pessoas criticam os discípulos de Jesus por não jejuarem: com base na antítese alegria vs. tristeza, Ferreira mostra a incompatibilidade desta com Jesus e, por consequência, com 
EID\&A - Revista Eletrônica de Estudos Integrados em Discurso e Argumentação, Ilhéus, n. 15, jan./jun.2018.

seus seguidores. Novamente, a argumentatividade do texto religioso ganha em persuasão por meio da estratégia metalinguística.

No Texto 4, a autora apresenta uma definição importante para a palavra jejum: aflição/tristeza (linha 3). Ao mesmo tempo, a autora identifica Jesus como o "noivo de uma festa de casamento" (linha 11), da "nova Aliança” estabelecida com Deus; seria a razão pela qual Jesus, em si, é motivo de alegria. Assim, argumenta-se a favor da não adesão dos discípulos de Jesus à noção de jejum, como tristeza/aflição. Tal relação nos leva a verificar uma nova ocorrência de transitividade:

a) Se jejum é tristeza/aflição

b) Se Jesus é alegria

Logo,

c) Jejum e Jesus são incompatíveis

Dessa forma, vale a pena relembrar que, ao deixar de lado o significado de abstinência para jejum, a autora apresenta um argumento mais forte para a não adesão dos discípulos; ao mesmo tempo, a relação de transitividade se aplica aos seguidores:

a) Se Jesus é alegria

b) Se o jejum é aflição

Logo

c) Os seguidores de Jesus devem estar alegres (e não jejuando/aflitos)

Texto 5 - CAMARGOS, Marcelo H. (2018). Lectionautas.

\begin{abstract}
Jesus ficou com muita pena do leproso que, ajoelhado a seus pés, pedia a cura. Outras traduções desse texto diriam que Jesus teve compaixão do doente, e decidiu curá-lo. A palavra compaixão tem origem no latim, e significa "entender a dor de outra pessoa" ou "é o ato de partilhar o sofrimento de outra pessoa". Saber dessa origem etimológica da palavra compaixão aprofunda e sensibiliza nosso olhar sobre Jesus. O Filho de Deus é aquele capaz de entender a dor do homem e é aquele disposto a partilhar nosso sofrimento.

Mas Jesus não apenas entende a dor e partilha o sofrimento. A compaixão gera vontade em Jesus ("Sim! Eu quero!) e propicia cura ("Você está curado"). Há nessa cena, portanto, uma manifestação da humanidade e da divindade de Jesus. Ele sente a dor como homem e cura como Deus.

E a cura oferecida por Jesus não apenas desinfecciona o corpo do leproso, livrando-o dos bacilos de Hansen, causadores da hanseníase, a lepra. Ao tocar o doente, Jesus combate sua marginalização e exclusão. Tocou o impuro, e ao tocar o impuro não se tornou impuro como ele, mas deu pureza ao impuro, reintegrando-o à sociedade. Da mesma forma Jesus age com o pecador. Ele alcança o pecador, e o seu toque clareia até a alma mais infeccionada pelo pecado, reintegrando-a ao reino de Deus.

Que Jesus tenha compaixão de nós.
\end{abstract}

Fonte: http://www.lectionautas.com.br/2018/marcos-140-45/ 
EID\&A - Revista Eletrônica de Estudos Integrados em Discurso e Argumentação, Ilhéus, n. 15, jan./jun.2018.

No texto 5, entre as linhas 2 e 4, Camargos apresenta o significado latino de "compaixão" para argumentar a força do trecho da cura de um leproso por parte de Jesus. Para o autor, a noção de "entender/partilhar o sofrimento" está diretamente relacionada com as características do Filho de Deus (linhas 5 e 6). O autor utiliza a expressão bíblica para trazer um argumento a favor da divindade de Jesus. Para além desse fato, o autor manifesta que a dupla natureza de Jesus (Deus e homem) é manifestada pela compaixão, que gera o sentimento de dor (humano) e a ação de curar (divina), especialmente entre as linhas 8 e 9. Para fechar, o autor apresenta, no final do trecho, um pedido pela compaixão de Jesus às pessoas (linha 15). Em outras palavras, parece argumentar que, por meio dessa compaixão, os fiéis poderão alcançar a cura de suas doenças (físicas ou espirituais, como indicara entre as linhas 10 e 13). Novamente, o recurso metalinguístico serve para a costura argumentativa do texto, levando o autor a buscar a adesão do leitor pela tese do seguimento a Jesus a partir da compreensão do texto bíblico.

No Texto 5, Camargos apresenta a definição de compaixão como entendimento/partilha de um sofrimento, argumentando que, ao utilizar essa expressão, pode-se compreender que o evangelista ressalta a humanidade de Jesus (sentir dor) e, ao mesmo tempo, sua divindade (curar o leproso porque sentiu compaixão). Na sequência, percebe-se novamente a ocorrência de um argumento por transitividade: o autor pede a compaixão de Jesus às pessoas, fazendo a seguinte relação:

a) Se a compaixão levou Jesus a curar o leproso;

b) Se Jesus tem compaixão de uma pessoa;

Logo,

c) Jesus cura essa pessoa.

Assim, conseguimos mostrar que todas as ocorrências apresentadas utilizam a metalinguagem como estratégia argumentativa em textos religiosos, mais especificamente utilizando argumentos quase lógicos, com predominância dos subtipos de definição e de transitividade. De algum modo, os autores se apoiam no significado de alguns termos para sustentar suas teses e defender o seguimento à doutrina cristã. Outro fato importante é que, com maior ou menor grau de complexidade técnica, os usos metalinguísticos são de entendimento acessíveis de público, o que parece, novamente, servir como um bom recurso de argumentatividade. 
EID\&A - Revista Eletrônica de Estudos Integrados em Discurso e Argumentação, llhéus, n. 15, jan./jun.2018.

\section{Considerações finais}

Este trabalho teve como objetivo principal defender que a metalinguagem presente em textos religiosos serve de estratégia argumentativa para a defesa do ponto de vista: os oradores, ao construir seus discursos com tais recursos, procuram obter a adesão do auditório para a tese defendida. Do ponto de vista da classificação apresentada, assumimos que, nos textos analisados, há a predominância de dois subtipos dos argumentos quase lógicos: o primeiro é o de definição, em que os autores apresentam definições ou etimologias das palavras; o segundo o da transitividade, já que estabelece relações entre essas definições e fatos/ações praticados por Jesus e/ou seus seguidores. Esperamos que este trabalho contribua para a compreensão das formas como os seres humanos agem por meio da linguagem e deixamos para futuros trabalhos análises com gêneros distintos.

\section{Fontes}

ANDRADE, Aíla L. Pinheiro de. Roteiros homilétivos (todos os santos). Vida Pastoral. Publicado em 05 de novembro de 2017. Disponível em: http://www.vidapastoral.com.br/roteiros/todos-os-santos-5-de-novembro/ Acesso em 05 fev. 2018.

CAMARGOS, Marcelo H. Marcos 1, 40-45. Lectionautas. Publicado em 11 jan. 2018. Disponível em: http://www.lectionautas.com.br/2018/marcos-140-45/ Acesso em 03 fev. 2018.

FERREIRA, Ana Paula. Jejum. Lectionautas. Publicado em 15 jan. 2018. Disponível em: http://www.lectionautas.com.br/2018/jejum/ Acesso em 05 fev. 2018.

KONINGS, Johan. Roteiros homiléticos (30. domingo do tempo comum). Vida Pastoral. Publicado em 21 de janeiro de 2018. Disponível em: http://www.vidapastoral.com.br/roteiros/30-domingo-do-tempo-comum-21-dejaneiro/. Acesso em: 05 fev. 2018.

PALAORO, Adroaldo. Palavras que destravam a vida. Dom Total. Publicado em 27 jan. 2018. Disponível em: http://domtotal.com/noticia/1226500/2018/01/palavras-quedestravam-a-vida/. Acesso em: 05 fev. 2018 
EID\&A - Revista Eletrônica de Estudos Integrados em Discurso e Argumentação, llhéus, n. 15, jan./jun.2018.

\section{Referências}

AUROUX, Sylvain. A revolução tecnológica da gramatização. Trad. Eni P. Orlandi. 3.ed. Campinas: Ed.UNICAMP, 2014.

CULIOLI, Antoine; NORMAND, Claudine. Onze rencontres sur le langage et les langues. Paris: Ophrys, 2005.

DUCROT, Oswald. O dizer e o dito. Trad. Eduardo Guimarães. Campinas: Pontes, 1987.

FIORIN, José Luiz. Argumentação. 1.ed. São Paulo: Contexto, 2017.

FRANCHI, Carlos. Linguagem: atividade constitutiva. Caderno de Estudos Linguísticos, Campinas, n.22, p. 9-39, jan./jun.1992.

GOMES-DA-SILVA, Edvânia. A metalinguagem nos gêneros da imprensa. Ao pé da letra, n. 1, p. 45-50, 1999.

KOCH, Ingedore G. Villaça. Argumentação e linguagem. 13.ed. São Paulo: Cortez, 2011.

PERELMAN, Chaïm; OLBRECHTS-TYTECA, Lucie. Tratado da Argumentação: a Nova Retórica. 3.ed. Trad. Maria Ermantina Galvão. São Paulo: Martins Fontes, 2014.

ROMERO, Márcia. Epilinguismo: considerações acerca de sua conceitualização em Antoine Culioli e Carlos Franchi. ReVEL, v. 9, n. 16, 2011.

WACHOWICZ, Teresa Cristina. Análise linguística nos gêneros textuais. 1.ed. Curitiba: IBPEX, 2010.

XAVIER, Antonio Carlos. A era do hipertexto: linguagem e tecnologia. Recife: Pipa Comunicação, 2013.

Forma de citação sugerida:

BERTUCCI, Roberlei Alves. Metalinguagem como recurso argumentativo em textos religiosos. EID\&A - Revista Eletrônica de Estudos Integrados em Discurso e Argumentação, Ilhéus, n. 15, p. 209-225, jan./jun.2018.

Recebido em: 08/02/2018

Aprovado em: 07/06/2018 